\title{
A lei de responsabilidade fiscal como um marco divisor na gestão pública brasileira: uma análise dos dezessete anos de sua implementação
}

A nação brasileira, ao longo de sua história, tem se deparado com uma sistemática prática de mal-uso das verbas públicas, que tanto solapa os maiores interesses nacionais. Diversos planos econômicos foram implementados, com vistas a melhor desenvolver o país, porém, a ausência de um arcabouço jurídico-fiscal consistente, capaz de moralizar a gestão pública, sempre se apresentou como uma barreira intransponível, frustrando a busca de suprir satisfatoriamente os anseios da população. No intuito de reverter esse quadro, foi criada, no ano 2000 , a Lei Complementar no 101, batizada de Lei de Responsabilidade Fiscal (LRF). O aludido diploma traz em seu bojo mecanismos esclarecedores acerca do que se espera do gestor público, que atue em qualquer uma das esferas de governo, ao definir princípios básicos de responsabilidade, transparência, bem como a aplicação de penalidades aos que descumprem seus preceitos, com vistas ao equilíbrio fiscal, expurgando a figura do déficit público, como também evitando o endividamento público irresponsável. Este artigo foi elaborado a partir de metodologia exploratória se utilizou de bibliografias e documentos, tendo como objetivo analisar o processo evolutivo da gestão pública brasileira, após o advento da Lei de Responsabilidade Fiscal, com base em experiências de ajuste fiscal bem-sucedidas, que culminaram com o atingimento do equilíbrio das finanças públicas da União Europeia, Estados Unidos e Nova Zelândia. Pretendeu-se ainda identificar os princípios que regem a transparência e o equilíbrio das finanças públicas, bem como explanar acerca da aplicabilidade das penalidades previstas no descumprimento dos preceitos da Lei Complementar 101/2000, tornando sua aplicação efetiva, produzindo resultados fiscais consistentes.

Palavras-chave: Gestão Pública; Equilíbrio Orçamentário; Transparência.

\section{The fiscal responsibility law as a dividing framework in Brazilian public management: an analysis of the seventeen years of its implementation}

\begin{abstract}
The Brazilian nation, throughout its history, has faced a systematic practice of misuse of public funds, which undermines the greatest national interests. Several economic plans were implemented, with a view to better developing the country, however, the absence of a consistent legal-fiscal framework, capable of moralizing public management, has always presented itself as an insurmountable barrier, frustrating the search to satisfactorily meet the needs of the country. population. In order to reverse this situation, in the year 2000, Complementary Law No. 101, named the Fiscal Responsibility Law (LRF), was created. The aforementioned diploma brings with it clarifying mechanisms about what is expected of the public manager, who acts in any of the spheres of government, by defining basic principles of responsibility, transparency, as well as the application of penalties to those who break their precepts, with a view to fiscal balance, purging the figure of the public deficit, as well as avoiding irresponsible public debt. This article was elaborated from an exploratory methodology, using bibliographies and documents, aiming to analyze the evolutionary process of Brazilian public management, after the advent of the Fiscal Responsibility Law, based on successful fiscal adjustment experiences, which culminated in achieving the balance of public finances in the European Union, the United States and New Zealand. It was also intended to identify the principles that govern the transparency and balance of public finances, as well as explaining the applicability of the penalties provided for failure to comply with the provisions of Complementary Law $101 / 2000$, making its application effective, producing consistent tax results.
\end{abstract}

Keywords: Public Management; Budgetary Balance; Transparency.

Topic: Gestão Pública

Reviewed anonymously in the process of blind peer

Ruy Alves Rodrigues Pinheiro (iD

Faculdade Educacional da Lapa, Brasil

http://lattes.cnpq.br/3403716802000806

http://orcid.org/0000-0002-2530-0558

planejamento.idaron@gmail.com

Geralda Genuína da Fonseca

Universidade Federal de Pernambuco, Brasil

http://lattes.cnpq.br/0427747763840759

http://orcid.org/0000-0002-8010-6205

geraldaidaron@hotmail.com

Júnior Cleber Alves Paiva (iD)

Faculdade de Ciências e de Tecnologia de Rondônia, Brasil

http://lattes.cnpq.br/1965873434054636

http://orcid.org/0000-0002-6938-4351

juniorcleber.ro@gmail.com

d

DOI: 10.6008/CBPC2179-684X.2020.004.0014
Received: 07/10/2020

Approved: 21/12/2020

\author{
Mariana Silveira de Oliveira (iD \\ Universidade Federal de Rondônia, Brasil \\ http://lattes.cnpq.br/2457376143665566 \\ http://orcid.org/0000-0001-5376-4598 \\ 15marianas@gmail.com \\ Rafael Luis da Silva (iD) \\ Universidade Federal de Rondônia, Brasil \\ http://lattes.cnpq.br/3368127484992279 \\ http://orcid.org/0000-0002-9485-479X \\ rafaeluismat@gmail.com
}

Referencing this:

PINHEIRO, R. A. R.; FONSECA, G. G.; PAIVA, J. C. A.; OLIVEIRA, M. S.; SILVA, R. L.. A lei de responsabilidade fiscal como um marco divisor na gestão pública brasileira: uma análise dos dezessete anos de sua implementação. Revista Brasileira de Administração Científica, v.11, n.4, p.178-188, 2020. DOI: http://doi.org/10.6008/CBPC2179684X.2020.004.0014 


\section{INTRODUÇÃO}

Quando nos debruçamos sobre o tema, Lei de Responsabilidade Fiscal - LRF é de bom alvitre conceituar, administração pública, haja vista que o aludido Diploma está a serviço da eficácia da gestão pública brasileira.

No entanto o conceito de administração pública não oferece contornos bem definidos, quer pela diversidade de sentidos da própria expressão, quer pelos diferentes campos em que se desenvolve a atividade administrativa. Para Meirelles (2008), a Administração Pública pode ser conceituada como "a gestão de bens e interesses qualificados da comunidade no âmbito federal, estadual ou municipal, segundo os preceitos do Direito e da Moral, visando ao bem comum". Já para Pietro (2005), o termo administração pública é visto sob dois ângulos, que merecem a devida atenção: sentido subjetivo ou formal e sentido objetivo ou material. O primeiro caso se refere à própria estrutura da administração, formada por entidades, órgãos e agentes políticos com suas respectivas competências que dão forma à Administração Pública. Por outro lado, ao se empregar o sentido objetivo ou material, está se fazendo alusão à própria atividade administrativa, que é exercida pelos respectivos entes, explicitado pelo fazer da administração em favor da coletividade, é a contrapartida estatal, é a entrega pelo estado dos bens ou serviços aos beneficiários à população.

Em suma, a administração pública nada mais é do que o meio de atingir o bem-estar social. Para tanto ensina Lima (2007) que "O fim, e não a vontade do administrador domina todas as formas da administração". Supõe, desta forma, a atividade administrativa a preexistência de uma regra jurídica, reconhecendo-lhe uma finalidade própria. "Repousa, consequentemente, a administração pública debaixo da legislação, que deve enunciar e determinar a regra de Direito" Lima (2007). O certo é que no desempenho dos encargos administrativos o agente do Poder Público não tem a liberdade de procurar outro objetivo, ou de dar fim diverso do prescrito em lei para a atividade. Não pode, assim, deixar de cumprir os deveres que a lei the impõe, nem renunciar a qualquer parcela dos poderes e prerrogativas que the são conferidos. Isso porque os deveres, poderes e prerrogativas não Ihe são outorgados em consideração pessoal, mas sim para serem utilizados em benefício da comunidade administrada. Descumpri-los equivalerá a desconsiderar a incumbência que aceitou ao defender os poderes necessários à consecução dos fins sociais, que constituem a única razão de ser da autoridade pública de que é investido.

Desta feita, o presente artigo tem como desígnio, analisar o processo evolutivo da gestão pública brasileira, após o advento da Lei de Responsabilidade Fiscal, com base em experiências de ajuste fiscal bemsucedidas de outros países, bem como, em conhecer como se implementaram as ações de gestão fiscal responsável, nos países analisados; identificar os princípios que regem o equilíbrio das finanças públicas brasileira; e abordar a aplicabilidade das penalidades previstas no descumprimento dos limites orçamentários pelos gestores públicos.

Ao analisar as diversificadas práticas empregadas na administração pública, é recorrente a nomeação de pessoas, para exercerem atividades de gestores públicos, sem que possuam as mínimas qualificações para 
o cargo, comprometendo a qualidade da gestão. É sabido que a administração pública brasileira carece de mecanismos eficazes de gestão responsável, e que há gestores que insistem em não se curvarem aos ditames da lei, que tem como propósito o equilíbrio fiscal. Com isso imerge o seguinte questionamento: por que ainda existe resistências por parte de gestores públicos em buscar o equilíbrio das finanças públicas?.

Provavelmente, trata-se de apego às antigas práticas de usar o orçamento público ao bel prazer, sem que houvesse qualquer punição, bem como a desconsideração do fato de que a Lei Complementar 101/2000, veio se pôr como um divisor de águas, para a administração pública brasileira, com o fito de melhor atender aos anseios da coletividade, dentro de um orçamento equilibrado.

Esta pesquisa foi desenvolvida nos meses de julho a dezembro de 2018, com a propositura de contribuir para solidificar em diversos atores (gestores, políticos, acadêmicos, entre outros) acerca da importância do preparo que deve ter aqueles responsáveis pela coisa pública, no sentido de que sejam protagonistas de uma gestão pública eficaz, haja vista não existir mais espaço para o improviso e ineficiência no âmbito da administração pública, e sim planejamento consistente, que quebre a barreira da busca pelo equilíbrio das finanças públicas.

Desta forma, é relevante entender que a Lei Complementar 101/2000, deve ser utilizada como um instrumento imprescindível para o gestor público responsável, haja vista que a sua observância, trará equilíbrio às contas públicas, desnudando a realidade fiscal, e concitando o gestor para a tomada de decisão consistente, justificando-se assim a temática da pesquisa.

\section{METODOLOGIA}

Nesta pesquisa foi utilizado o método de abordagem dedutivo, que segundo Marconi et al. (2003), parte "das teorias e leis, na maioria das vezes prediz a ocorrência dos fenômenos particulares (conexão descendente)". A aludida pesquisa possui cunho bibliográfico, pois está fundamentada em um apanhado, sobre os principais trabalhos já realizados, revestidos de importância, por serem capazes de fornecer dados atuais e relevantes, relacionados com a temática, cujas fontes de dados foram: livros, artigos, periódicos, teses e jornais.

\section{DISCUSSÃO TEÓRICA}

\section{A lei de Responsabilidade Fiscal}

A Lei Complementar no 101, de 04/05/2000, popularmente conhecida como Lei de Responsabilidade Fiscal - LRF entrou no mundo jurídico brasileiro como uma das mais importantes ferramentas para determinar diretrizes necessárias para uma boa execução do erário público. Ela trouxe um aspecto de completude, sem, contudo, ter a pretensão de ser uma lei salvadora, para sanar todos os problemas na execução da gestão pública. Outras leis foram e são igualmente importantes, como por exemplo a Lei № 4.320/64, que há mais de cinquenta anos, normatiza as finanças públicas no Brasil.

A LRF veio como uma atalaia, que aciona a trombeta diante de um perigo iminente, acrescentando 
uma série de comandos e condicionamentos, com vistas a prezar pela eficácia na gestão e pelo equilíbrio fiscal nas contas públicas brasileira, proporcionado avanços importantes em termos econômicos e sociais, concitando uma concentração de esforços de todos os seguimentos envolvidos na gestão da coisa pública (MOTTA, 2002). Trouxe inovações no processo de discussão e elaboração do planejamento no setor público reforçando os mecanismos de controle e transparência da aplicação dos recursos, atribuindo aos administradores a responsabilidade pela gestão fiscal. Ressalte-se que a lei implantou a exigência da transparência na gestão pública, socializando-a através da publicação de relatórios e demonstrativos da execução orçamentária, apresentando ao contribuinte a utilização dos recursos que ele coloca à disposição dos governantes. A responsabilidade pela gestão fiscal pressupõe a ação planejada e transparente que objetiva prevenir riscos e corrigir desvios capazes de afetar o equilíbrio das contas públicas, mediante cumprimento de metas, obediência à limites, condições para renúncia de receita e geração de despesas com pessoal, dívida, dentre outros.

A mesma lei atribuiu aos Tribunais de Contas a fiscalização das normas então introduzidas. De fato, a Lei Complementar $n^{\circ} 101 / 00$ traz regulação para receitas e despesas públicas com o objetivo de equilibrar estes dois fatores, permitindo que o saneamento financeiro do Estado proporcione uma atuação mais eficaz em benefício dos interesses da sociedade. Portanto, o diploma legal em apreço desenha um sistema integrado aos três níveis de governo, individualizando responsabilidades de cada poder e de seus titulares, ou substitutos no exercício da administração dos vários organismos auxiliares, tanto da administração pública direta como indireta. $O$ desenho inclui mecanismos implícitos de disciplina e implementação das medidas de Transparência da Gestão Fiscal e de atendimento aos dispositivos de responsabilidade e integração. Toda a integração é desenhada como forma de alavancagem para um sistema responsável de gestão fiscal e administrativa. A Lei de Responsabilidade Fiscal, prevê no seu art. 1ㅇ, $\S 1$ 을 a responsabilidade de se buscar promover uma gestão fiscal e orçamentária responsável:

A responsabilidade na gestão fiscal pressupõe a ação planejada e transparente, em que se previnem riscos e corrigem desvios capazes de afetar o equilíbrio das contas públicas, mediante o compromisso de metas e resultados entre receitas e despesas e a obediência à limites e condições no que tange a renúncia de receita, geração de despesas com pessoal, da seguridade social e outras, dívidas consolidada e mobiliária, operações de crédito, inclusive por antecipação de receita, concessão de garantia e inscrição em restos a pagar.

\section{A Transparência na Gestão Pública}

Transparência e responsabilidade são os pilares básicos da LRF. Como todo modelo eficiente, a lei baseia-se em um princípio simples, não gastar mais do que se arrecada. A LRF estabelece condições para que possam ocorrer transparências nos recursos públicos aplicados, e neste contexto a gestão pública transparente caracteriza-se pelo acesso às informações compreensíveis para todo o cidadão, afinal de contas os recursos administrados pelos setores públicos são oriundos dos cidadãos na forma de contribuintes. Além do mais, a sociedade que recolhe tributos começa cada vez mais a exigir respostas aos seus anseios e necessidades. Busca-se resultados decorrentes de uma eficiente aplicação dos recursos, na prestação de serviços cada vez melhores, com eficiência e qualidade. 
A Lei de Responsabilidade Fiscal, em seu artigo 48, prevê o seguinte:

São instrumentos de transparência da gestão fiscal, aos quais será dada ampla divulgação, inclusive em meios eletrônicos de acesso público: os planos, orçamentos e leis de diretrizes orçamentárias; as prestações de contas e o respectivo parecer prévio; o Relatório Resumido da Execução Orçamentária e o Relatório de Gestão Fiscal; e as versões simplificadas desses documentos.

Parágrafo único. A transparência será assegurada também mediante incentivo à participação popular e realização de audiências públicas, durante os processos de elaboração e de discussão dos planos, lei de diretrizes orçamentárias e orçamentos.

Portanto, a ampla divulgação deve ocorrer inclusive em meios eletrônicos, seja em site próprio ou não, consoante preceitua o art. 48 da LRF e os princípios norteadores da administração pública, sem prejuízo do disposto no art. 49 da mesma lei. Não ocorrendo à ampla divulgação, certamente deverá atuar os órgãos responsáveis pela fiscalização, a fim de fazer cumprir o comando normativo, adotando as medidas pertinentes.

É fundamental a participação do cidadão nas decisões que resultem na prestação daqueles serviços ou que se refiram a ações que venham prejudicar o bem-estar coletivo. E para tanto, a LRF trouxe uma contribuição muito importante para a transparência da gestão fiscal, ao definir que os relatórios fiscais, devam ter ampla divulgação, assegurando inclusive a participação da sociedade na discussão dos Plano Plurianual - PPA, Lei de Diretrizes Orçamentárias - LDO e Lei Orçamentária Anual - LOA.

Atualmente um dos instrumentos para que tudo isso se concretize são as audiências públicas, instituídas pela LRF com o objetivo de oferecer à sociedade oportunidade de participar nas decisões políticas de alocação dos recursos públicos, exercitar o princípio da transparência e motivar o controle social dos atos da administração.

Com base nos parâmetros da LRF, a sociedade organizada, além de exercer o direito de voto para eleger o administrador público, tem efetiva oportunidade de participar do processo de administração pública de forma mais intensa. Portanto, se a participação popular na elaboração dos projetos orçamentários está hospedada na nova ordem jurídica, a LRF inova quando determina que haja um monitoramento quadrimestral, no final dos meses de maio, setembro e fevereiro, ocasião em que o Poder Executivo demonstrará e avaliará o cumprimento das metas de receita, despesa e montante da dívida pública de cada quadrimestre, em audiência pública na comissão de orçamento da Casa Legislativa (art. 9o, § 4o da LRF). É a possibilidade do acompanhamento direto pelo povo da execução do orçamento.

Quanto à indicação das prestações de contas e o respectivo parecer prévio como instrumento de transparência da gestão fiscal, dispõe a LRF que as contas apresentadas pelo Chefe do Poder Executivo ficarão disponíveis, durante todo o exercício, no respectivo Poder Legislativo e no órgão técnico responsável pela sua elaboração, para consulta e apreciação pelos cidadãos e instituições da sociedade (LRF, art. 49).

\section{O Planejamento Orçamentário da Administração Pública}

Na administração pública, a Lei Orçamentária Anual - LOA, se reveste de grande importância pois tem por finalidade a concretização dos objetivos e metas estabelecidas no Plano Plurianual - PPA, que é o 
instrumento de planejamento governamental de médio prazo, com vigência de quatro anos (CARVALHO, 2008). A LOA é um processo contínuo, dinâmico e flexível, que traduz, em termos monetários para um exercício financeiro, os planos e programas de trabalho do governo. É o cumprimento ano a ano das etapas do PPA, em consonância com a Lei de Diretrizes Orçamentária - LDO e a LRF. A LOA é o instrumento mais importante de gerenciamento orçamentário e financeiro da Administração Pública, sua principal finalidade é administrar o equilíbrio entre receitas e despesas públicas, evitando endividamento irresponsável (CARVALHO, 2008).

Acima de tudo, precipuamente, em tese, a LRF institui mecanismos mais rigorosos para os gestores das finanças públicas nas três esferas de governo, devendo estes observá-los, sob pena de crime de responsabilidade. As principais mudanças foram sobre a prática de muitos gestores de transferir as dificuldades fiscais, para administrações e gerações futura, sendo que as autoridades governamentais e agentes públicos passaram a ser responsabilizados criminalmente pela má gestão dos recursos públicos e pelos atos que causam danos ao erário (ALBUQUERQUE, 2008).

O Orçamento Público é a estimativa de receita e fixação da despesa de um governo em determinado período e deve ser aprovado por lei. Os princípios orçamentários são diretrizes que devem ser respeitadas na confecção e no controle dos orçamentos, estão previstos nos artigos 165 a 169 da Constituição Federal, na Lei 4.320/1964 e na Lei de Responsabilidade Fiscal (FONTENELLE, 2003).

O objetivo do orçamento público é explicitar à população, de maneira transparente, qual o montante de despesa e investimento públicos anual que será executado pelo estado, tendo como base a expectativa de arrecadações tributárias que estiverem autorizadas pela lei orçamentária (BASTOS, 1992).

\section{O Dever de Prestar Contas}

O dever de prestar contas é decorrência natural da administração como encargo de gestão de bens e interesse alheios. Se o administrar corresponde ao desempenho de um mandato de zelo e conservação de bens e interesse de outrem, manifesto é que quem o exerce deverá prestar contas ao proprietário. No caso do administrar público, esse dever se apresenta ainda mais compulsório, porque a gestão se refere aos bens e interesses da coletividade e assume o caráter de um múnus público, isto é, de um encargo para com a comunidade. Daí o dever indeclinável de todo administrador público - agente político ou simples funcionário - de prestar contas de sua gestão administrativa, e nesse sentido é a orientação de nossos tribunais.

A prestação de contas não se refere apenas aos dinheiros públicos, à gestão financeira, mas a todos os atos de governo e administração. Não será necessário muito perquirir nos domínios de nosso Direito Positivo para se chegar a essa conclusão. A própria Constituição Federal, quando garante a obtenção de certidões das repartições públicas "para a defesa de direitos e esclarecimento de situações" (art. 5 , XXXIV, "b"), e as leis administrativas, quando exigem a publicidade dos atos e contratos da Administração, estão a indicar que o administrador público deve contas de toda sua atuação aos administrados. Esse dever de prestar contas mais se acentua na gestão financeira, onde a Carta da República o impõe expressamente (art. 70 a 75) não só para os administradores como para os demais responsáveis por bens e valores públicos 
(MEIRELLES, 2008).

\section{As infrações e penalidades}

A LRF trouxe um elenco de infrações que a Administração Pública, no exercício de suas atividades pode incorrer, tais infrações carregam consigo as correspondentes penalidades; no quadro a seguir elencamos quatro dessas infrações:

Quadro 1: Principais infrações públicas.

\begin{tabular}{|c|c|}
\hline Infração & Penalidade \\
\hline $\begin{array}{l}\text { Deixar de apresentar e publicar o Relatório de } \\
\text { Gestão Fiscal, no prazo e com o detalhamento } \\
\text { previsto na lei (LRF, artigos } 54 \text { e 55; Lei no } \\
\text { 10.028/2000, art. 5o, inciso I). }\end{array}$ & 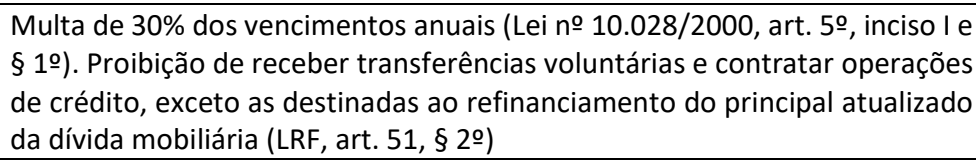 \\
\hline $\begin{array}{l}\text { Ultrapassar o limite de Despesa Total com Pessoal } \\
\text { em cada período de apuração (LRF, art. } 19 \text { e 20). }\end{array}$ & Cassação do mandato (Decreto-Lei no 201, art. 4으, inciso VII). \\
\hline $\begin{array}{l}\text { Expedir ato que provoque aumento da Despesa } \\
\text { com Pessoal em desacordo com a lei (LRF, art. 21). }\end{array}$ & $\begin{array}{l}\text { Nulidade do ato (LRF, art. 21); Reclusão de um a quatro anos (Lei no } \\
10.028 / 2000 \text {, art. 2o) }\end{array}$ \\
\hline $\begin{array}{l}\text { Não cumprir limite de Despesa Total com Pessoal } \\
\text { em até dois anos, caso o Poder ou órgão tenha } \\
\text { estado acima desse limite em } 1999 \text { (LRF, art. 70). }\end{array}$ & $\begin{array}{l}\text { Proibição de receber transferências voluntárias, contratar operações de } \\
\text { crédito e de obter garantias (LRF, art. 23, § } 3 \% \text { ). Cassação do mandato } \\
\text { (Decreto-Lei no 201, art. 4ㅇ, inciso VII). }\end{array}$ \\
\hline
\end{tabular}

\section{Histórico da Criação da Lei de Responsabilidade Fiscal - Origens e Experiências Anteriores}

Apesar de seu aspecto inovador, e sua adaptabilidade às três esferas de governo União Federal, Estados, Distrito Federal e Municípios, além de alcançar os Poderes Executivo, Legislativo e Judiciário, a Lei de Responsabilidade Fiscal, se espelha na experiência internacional recente. Em período não muito distante, na década de 90, o mundo começou a despertar para a responsabilidade fiscal. Alguns países empreenderam iniciativas bem-sucedidas no sentido perseguir o equilíbrio de suas finanças, antecipando-se aos fatos, se prevenindo, com vistas a evitar o surgimento de grandes déficits públicos e níveis excessivos de endividamento (DOIA, 2016).

Ao retroagir no tempo na busca de experiências bem-sucedidas de outros países, no que concerne ao equilíbrio fiscal de suas contas públicas, a Lei de Responsabilidade Fiscal impregnou alguns princípios e normas, como as modelagens tomadas como referencial para a sua elaboração, cujas bases são alicerçadas nas experiências da União Europeia, dos Estados Unidos da América, e da Nova Zelândia, conforme os tópicos vindouros.

\section{A experiência da União Europeia}

O marco inicial é o Tratado de Maastricht, de 1992, cujos critérios foram concebidos como condição para o ingresso na União Monetária Europeia, no intuito de evitar que um país membro gerasse externalidades negativas para outros. Desta maneira, os Estados-Membros, não obstante autônomos e soberanos, conduziriam com relativa independência suas políticas, as quais deveriam convergir para os critérios acordados (TAVARES et al., 1999).

A disciplina fiscal foi então eleita como um dos quatro pilares para acessão ao EURO, ao lado da estabilidade de preços (a taxa de inflação não deveria ultrapassar em mais de 1,5\% a taxa de inflação dos 
três Estados-Membros com melhores resultados em termos de estabilidade de preços); estabilidade das taxas de juros de longo prazo (que não poderiam ultrapassar em mais de $2 \%$ as taxas dos três EstadosMembros com as melhores taxas de inflação no ano precedente); e da estabilidade cambial (que tinham de permanecer, pelos dois anos precedentes, dentro de margens de flutuações definidas, sem ter procedido a uma desvalorização em relação à moeda de qualquer outro Estado-Membro) (SANTOS, 2007).

Outro aspecto que também chamou atenção na experiência da Comunidade Econômica Europeia foi o fato de que as regras, ainda que quantitativas, não eram rígidas. Eram admitidos desvios desde que mantida a tendência de ajuste. Mais importante que atingir uma meta era demonstrar a trajetória de convergência para o objetivo desejado.

Conquanto alguns autores mencionem a experiência europeia como exemplo a ser observado na implementação da política fiscal em uma estrutura federativa (TAVARES et al., 1999), outros criticam a recepção desse modelo no ordenamento jurídico brasileiro. Santos (2007) enfatiza uma marcante assimetria entre os dois sistemas, especialmente no tocante aos quadros fático e institucional que circundaram a elaboração de cada um dos programas.

\title{
A experiência dos Estados Unidos da América
}

No ponto de vista histórico, nos Estados Unidos, o surgimento de grandes déficits, a partir da década de 70, tornava cada vez mais urgente a necessidade de se estabelecer limites fiscais.

Após algumas tentativas não exitosas, em 1990, foi realizado um novo esforço, agora mais assentado em regras de procedimentos: os Estados Unidos adotaram o Budget Enforcement Act - Lei de Cumprimento do Orçamento, que abandonou foco no déficit, passando a conter rigidamente a despesa e a garantir o nível básico de arrecadação (baseline). O diploma introduziu mecanismo de corte automático para as despesas discricionárias sempre que as previsões indicassem o não cumprimento das metas de resultado fiscal fixadas pelo Congresso Tavares et al. (1999), e estabeleceu restrição à apresentação de novas despesas compulsórias sem a indicação das respectivas fontes de financiamento - o sistema PAYGO.

\begin{abstract}
Na lei brasileira, esses mecanismos podem ser traduzidos respectivamente para limitação de empenho e compensação. A limitação de emprenho (sequestration) consiste na proibição de empenhar com o estrito propósito de garantir a eficácia dos limites e das metas orçamentárias estabelecidas para as receitas e despesas. [...] a compensação (pay as you go) parte do princípio da "neutralidade orçamentária", ou seja, qualquer ato que provoque aumento de despesas deve ser devidamente compensado com o aumento permanente de receitas ou redução permanente de despesas. [...] no modelo americano esses dois mecanismos se complementam na busca do equilíbrio fiscal. (FIGUEIREDO, 2001)
\end{abstract}

Desse modo, se novas alocações de recursos resultassem em aumento dos limites fixados para as despesas discricionárias, o Presidente deveria sequestrar recursos orçamentários suficientes para compensar o gasto em excesso. De outra parte, as despesas com a criação de um novo programa ou a ampliação de um já existente que provocassem elevação de déficit apenas seriam aprovadas caso acompanhadas de um correspondente aumento de receitas ou de um corte nas despesas dos demais programas obrigatórios. Relatório do U. S. Congressional Budget Office - CBO (Comitê de Finanças de Senados dos EUA) divulgado em 2001 atribuiu à lei em comento relevante papel no controle do déficit público, tendo o equilíbrio 
orçamentário sido alcançado em 1998, quatro anos antes da data fixada (LIMA, 2002).

Ressalte-se que o Budget Enforcement Act, ao contrário da Lei de Responsabilidade Fiscal, aplica-se unicamente ao governo federal. Por conseguinte, a mesma crítica feita por alguns autores à adoção do modelo da União Europeia repete-se ante a experiência dos Estados Unidos (FIGUEIREDO, 2001).

\section{A experiência da Nova Zelândia}

A experiência da Nova Zelândia é marcada por diferenças significativas, em relação às experiências compiladas da Comunidade Econômica Europeia e dos Estados Unidos, até aqui analisadas. Na Lei de Responsabilidade Fiscal da Nova Zelândia, de 1994, a transparência se sobrepõe à rigidez das regras. Basicamente, a Lei possui princípios, algumas poucas regras e muita transparência, inclusive com a exigência de publicação de diversos relatórios periódicos, com todo o tipo de informação fiscal e diferentes níveis de detalhamento.

O Departamento de Tesouro da Nova Zelândia, em 1995, sumarizou os cinco objetivos do FRA: aumentar a transparência das intenções políticas e os impactos fiscais e econômicos das políticas; trazer uma visão de longo prazo para o orçamento; antecipar o impacto agregado do orçamento, evidenciando-o antes da definição da alocação anual detalhada; assegurar relatórios independentes de avaliação da política fiscal e facilitar o exame dos parlamentares e do público em geral dos planos e informações fiscais e econômicas (LIMA, 2002).

Para alcançá-los, foram estabelecidos cinco princípios de administração fiscal responsável (RICHARDSON, 1998): 1. Reduzir a dívida pública para níveis prudentes, por meio de superávits anuais. Reitere-se, não há indicação do nível de endividamento a ser atingido, cabendo a cada governo defini-lo; 2 . Atingindo-se níveis prudentes de endividamento, mantê-los; 3. Alcançar níveis de valor líquido do Estado que possam atenuar impactos negativos; 4. Administrar prudentemente os riscos fiscais; 5 . Perseguir políticas compatíveis com um razoável grau de previsibilidade sobre o nível e a estabilidade das alíquotas tributárias.

Em que pese a ausência de imposição de metas rígidas ao déficit e à dívida, o Fiscal Responsibility Act obriga o governo a justificar as razões do desempenho no caso de inobservância dos princípios (LIMA, 2002).

O modelo da Nova Zelândia exerceu expressiva influência sobre a Lei Complementar no 101/2004, que instituiu a ação transparente como pressuposto da gestão fiscal responsável, inaugurando um novo padrão contábil e prevendo uma série de relatórios gerenciais.

O Parlamento fixa critérios de desempenho de forma genérica e o Poder Executivo tem liberdade para orçar e gastar, desde que com amplo e estrito acompanhamento da sociedade de todas as etapas de gasto. Fala-se em nível prudente de dívida e prazo razoável para equilibrar o orçamento. Entretanto, quem define esses conceitos é o próprio governo, que deve justificar ao Parlamento e ao público em geral sua interpretação do que é prudente e razoável.

A experiência neozelandesa foi uma referência importante para os dispositivos de transparência da Lei de Responsabilidade Fiscal. Um dos exemplos mais marcante é o Relatório de Gestão Fiscal. Inspirado na Declaração de Responsabilidade Fiscal, da Nova Zelândia, deve ser publicado em meio de amplo acesso 
público, inclusive na internet, a cada quatro meses. É assinado pelos chefes de cada Poder, de cada ente da federação, que nele devem dizer se estão cumprindo os limites que a Lei de Responsabilidade Fiscal estabelece para dívida, pessoal, operações de crédito e garantias. Se não estão cumprindo, devem explicarIhes as razões, quais as medidas adotadas e a adotar para que os limites venham a ser cumpridos, e em que tempo se espera que surtam os efeitos preconizados pela lei. Esse procedimento se repete a cada quatro meses, de modo que fica difícil para o governante fantasiar ou abster-se de dar explicações, e fica fácil para o cidadão acompanhar as ações do governo.

Essa experiência, considerada um paradigma internacional de transparência nas finanças públicas, segundo Kopits et al. (1998), não poderia deixar de ser considerada na elaboração da Lei de Responsabilidade Fiscal do Brasil.

\section{CONCLUSÕES}

Portanto, o objetivo desta pesquisa foi atingido, ao considerar a situação da gestão pública brasileira, antes e depois do advento da Lei de Responsabilidade fiscal, onde se constatou o colecionamento de diversos benefícios, entre os quais destacamos: A transparência, como pressuposto para uma gestão fiscal responsável. A Lei prevê a divulgação de inúmeros demonstrativos e relatórios periódicos, inclusive em meios eletrônicos de acesso público, dentre eles, o Relatório de Gestão Fiscal, que deve ser emitido a cada quadrimestre e publicado até trinta dias. Ao final do exercício, haverá a consolidação desses relatórios parciais, resultando na prestação de contas anual da gestão fiscal.

O Planejamento Orçamentário da Administração Pública - A Lei Orçamentária Anual - LOA, se reveste de grande importância pois tem por finalidade a concretização dos objetivos e metas estabelecidas no Plano Plurianual - PPA, que é o instrumento de planejamento governamental de médio prazo, com vigência de quatro anos. A LOA é o instrumento mais importante de gerenciamento orçamentário e financeiro da Administração Pública, sua principal finalidade é administrar o equilíbrio entre receitas e despesas públicas, evitando endividamento irresponsável.

O Dever de Prestar Contas na Administração Pública se apresenta ainda mais compulsório, porque a gestão se refere a bens e interesse da coletividade e assume o caráter de um múnus público, isto é, de um encargo para com a comunidade. Daí o dever indeclinável de todo administrador público - agente político ou simples funcionário - de prestar contas de sua gestão administrativa, e nesse sentido é a orientação de nossos tribunais.

Em caso de não cumprimento de suas normas, a LRF estabelece diversas sanções institucionais e pessoais. São exemplos de sanção institucional: suspensão das transferências voluntárias para aquele governo que não instituir, prever e arrecadar impostos de sua competência.

Além das sanções institucionais há as sanções pessoais, previstas em um projeto de lei ordinária denominada Lei de Crimes de Responsabilidade Fiscal, que prevê que os governantes poderão ser responsabilizados pessoalmente e punidos com a perda de cargo, inabilitação para exercício de emprego público, prisão e multa. 


\section{REFERÊNCIAS}

ALBUQUERQUE, C.; MEDEIROS, M.; FEIJÓ, P. H.. Gestão de finanças públicas. 2 ed. Brasília: Gestão Pública, 2008.

BRASIL. Lei complementar n. 101, de 04 de maio de 2000 (Lei de Responsabilidade Fiscal). Estabelece normas de finanças públicas voltadas para a responsabilidade na gestão fiscal e dá outras providências. Brasília: DOU, 2000.

BRASIL. Lei n. 4.320, DE 17 de março de 1964. Estatui Normas Gerais de Direito Financeiro para elaboração e controle dos orçamentos e balanços da União, dos Estados, dos Municípios e do Distrito Federal. Brasília: DOU, 1964.

BRASIL. Lei $\mathbf{n}$. 10.028, de 19 de outubro de 2000. Altera o Decreto-Lei no 2.848, de 7 de dezembro de 1940: Código Penal, a Lei no1.079, de 10 de abril de 1950, e o Decreto-Lei no 201, de 27 de fevereiro de 1967. Brasília: DOU, 1964.

BRASIL. Decreto-Lei n. 201, de 27 de fevereiro de 1967. Dispõe sobre a responsabilidade dos Prefeitos e Vereadores, e dá outras providências. Brasília: DOU, 2000.

BASTOS, C. R.. Curso de direito financeiro e de direito tributário. 2 ed. São Paulo: Saraiva, 1992.

CARVALHO, D.. Orçamento e contabilidade pública: teoria, prática e mais de 800 exercícios. 4 ed. Rio de Janeiro: Elsevier, 2008.

DOIA, A. R. L.. A importância da lei de responsabilidade fiscal para a administração pública. Revista Científica Multidisciplinar Núcleo do Conhecimento, v.7, p. 24-36, 2016.

FIGUEIREDO, C. M. C.. Comentários à lei de responsabilidade fiscal. 2 ed. São Paulo: Revista dos Tribunais, 2001.

FONTENELE, A. M.. O orçamento público no Brasil: uma visão geral. Jus Navigandi, Teresina, v.7, n.62, 2003.
KOPITS, G.; CRAIG, J.. Transparency in Government

Operations. Washington: IMF, 1998.

LIMA, R. C.. Princípios do direito administrativo. 7 ed. São Paulo: Malheiros Editores, 2007.

LIMA, E. C. P.. Disciplina fiscal no Brasil: atuais instituições garantem equilíbrios permanentes?. In: PRÊMIO TESOURO NACIONAL, TÓPICOS ESPECIAIS DE FINANÇAS PÚBLICAS, 7. Anais. Brasília: ESAF, 2002.

MARCONI, M. A.; LAKATOS, E. M.. Fundamentos da metodologia científica. 5 ed. São Paulo: Atlas, 2003.

MEIRELLES, H. L.. Direito Administrativo Brasileiro. 34 ed. São Paulo: Malheiros, 2008.

MOTTA, C. P. C.. Eficácia nas Licitações e Contratos: estudos e comentários sobre a Lei 8.666/93 e 8.987/95, a nova modalidade do pregão, impacto da Lei de Responsabilidade Fiscal. 9 ed. Belo Horizonte: Del Rey, 2002.

PIETRO, M. S. Z.. Direito administrativo. 18 ed. São Paulo: Atlas, 2005

RICHARDSON, R.. As reformas no setor público da Nova Zelândia. In: BRESSER-PEREIRA, L. C.; SPINK, P.. Reforma do estado e administração pública gerencial. Rio de Janeiro: Fundação Getúlio Vargas, 1998.

SANTOS, F. C.. Lei de responsabilidade fiscal $x$ Stability and Crowth Pact. Brasília: ESAF, 2007.

TAVARES, M. A. R.; MANOEL, A.; AFONSO, J. R. R.; NUNES, S. P. P.. Princípios e regras em finanças públicas: a proposta da lei de responsabilidade fiscal no Brasil. Versão modificada de trabalho intitulado 'Uma proposta para um novo regime fiscal no Brasil: o da responsabilidade fiscal'. In: SEMINÁRIO REGIONAL DE POLÍTICA FISCAL DA CEPAL, 11. Anais. Brasília, 1999.

A CBPC - Companhia Brasileira de Produção Científica (CNPJ: 11.221.422/0001-03) detém os direitos materiais desta publicação. Os direitos referem-se à publicação do trabalho em qualquer parte do mundo, incluindo os direitos às renovações, expansões e disseminações da contribuição, bem como outros direitos subsidiários. Todos os trabalhos publicados eletronicamente poderão posteriormente ser publicados em coletâneas impressas sob coordenação da Sustenere Publishing, da Companhia Brasileira de Produção Científica e seus parceiros autorizados. Os (as) autores (as) preservam os direitos autorais, mas não têm permissão para a publicação da contribuição em outro meio, impresso ou digital, em português ou em tradução. 